\title{
Primordial eukaryotes in a Paleoproterozoic sea
}

\author{
BENJAMIN J. NeTtERSHEIM ${ }^{1,2}$, JOCHEN J. BROCKS ${ }^{2}$
}

${ }^{1}$ Max-Planck-Institute for Biogeochemistry (bnett@bgcjena.mpg.de), ${ }^{2}$ Research School of Earth Sciences, Australian National University

Molecular fossils point to a rise of algae to ecological dominance $\sim 0.8$ to 0.6 billion years (Gy) ago. Yet, preceding this event, we know little about the ecological importance of eukaryotes. The fossil record suggests that eukaryotes emerged more than 1.6 Gy ago. Yet, these early microfossils provide little information on the ecological significance of early eukaryotes and cannot be confidentially assigned to extant groups [1]. The oldest evidence for modern-like crown-group eukaryotes is provided by $\sim 1 \mathrm{Ga}$ microfossils of red algae [2], while the record of unambigously syngenetic saturated steranes, the molecular fossils of eukaryotes, dates back to $\sim 0.8$ Gy [3]. However, we know little about where, when and under which environmental conditions eukaryotes flourised before this time, and the ecological role and evolutionary history is thus enigmatic for most part of the $>1.6$ Gy that eukaryotes inhabited our planet.

The oldest unambiguously syngenetic biomarkers on Earth are found in $\sim 1.64 \mathrm{Ga}$ old rocks from the Barney Creek Formation (BCF), deposited in a largely anoxic marine basin. A unique 4-methyl-dominance of triaromatic steroids pointed towards methanotrophic bacteria, but the absence of saturated equivalents (i.e. steranes) remained enigmatic [4]. Here we provide the most detailed description of the BCF steroid inventory, reporting an array of novel biomarkers-including the oldest syngenetic sterol derivatives plausibly derived from primordial eukaryotes or mixed stem-group eukaryotic and bacterial sources. Using laboratory experiments to mimick the geological alteration of biosynthetic intermediates of sterol biosynthesis, we demonstrate that the diverse $\mathrm{BCF}$ fossil sterols likely derive from the earliest products of the sterol biosynthetic pathway. Their high abundance in BCF rock extracts suggests that the source organisms, possibly including early eukaryotic ancestors, may have been more abundant during Earth's Middle Ages than currently thought, while the concomitant absence of typical crown-group steranes suggests that more modern crown-group forms had not yet evolved or where ecologically insignificant.

[1] Knoll \& Nowak (2017) Sci Adv 3, 1-14. [2] Butterfield et al. (1990) Science 250, 104-7. [3] Brocks et al. (2017) Nature 548, 578-81. [4] Brocks et al. (2005) Nature 437, 866-70. 